\title{
PENGARUH LAMA PENYIMPANAN TERHADAP AKTIVITAS ANTIOKSIDAN EKSTRAK DAUN MIANA (Coleus atropurpureus L. Benth)
}

\author{
Husnul Khotimah ${ }^{1, *}$, Risna Agustina ${ }^{1,2}$, Mirhansyah Ardana ${ }^{1,3}$ \\ ${ }^{1}$ Laboratorium Penelitian dan Pengembangan Kefarmasian "Farmaka Tropis" \\ Fakultas Farmasi, Universitas Mulawarman, Samarinda, Indonesia \\ ${ }^{2}$ Kelompok Keilmuan Farmasi Klinik dan Komunitas, Fakultas Farmasi, \\ Universitas Mulawarman, Samarinda, Indonesia \\ ${ }^{3}$ Kelompok Keilmuan Teknologi Farmasi, Fakultas Farmasi, Universitas Mulawarman, \\ Samarinda, Indonesia \\ *Email: Husnulkh1797@gmail.com
}

\begin{abstract}
Miana leaves (Coleus atropurpureus L. Benth.) are plants that have natural antioxidant activity. This study aims to determine the effect of duration storage on antioxidant activity and total flavonoids of Miana leaf extract (Coleus atropurpureus L. Benth.) in cool storage.Total flavonoids test and antioxidant activity test using DPPH (1,1-diphenyl-2picrylhydrazyl) method and measured by UV-Vis spectrophotometer and calculate the $I C_{50}$.value. The results indicate the antioxidant activity in Miana leaf extract that stored in a cool temperature had increased activity and after two weeks of storage antioxidant activity began to decline, this is not in line with the level of total flavonoids which decreased on the third day after storage.Therefore, it was thought the extract have other compounds also provides antioxidant activities such as positive tannin contained in the leaves of Miana on the results of testing of secondary metabolites and tanninis one of the compounds that can support the antioxidant activity of extracts. The conclusion of this study is the antioxidant activity of Miana leaves had increased during a week of storage in acool temperature and began to decline after two weeks of storage.
\end{abstract}

Keywords: Antioxidants; Miana Leaves; $I_{50}$; Duration of storage; Stability

\begin{abstract}
ABSTRAK
Daun miana (Coleus atropurpureus L. Benth.) merupakan tumbuhan yang memiliki aktivitas antioksidan alami.Tujuan penelitian ini yaitu untuk mengetahui pengaruh lama penyimpanan terhadap aktivitas antioksidan dan flavonoid totalekstrak daun Miana (Coleus atropurpureus L. Benth.) pada penyimpanan suhu sejuk. Dilakukan pengujian flavonoid total serta uji aktivitas antioksidanmenggunakan metode DPPH (1,1-difenil-2pikrilhidrazil) dan diukur dengan spektrofotometer $U V$-Vis, kemudian dihitung nilai $\mathrm{IC}_{50}$. Hasil penelitian menunjukkan aktivitas antioksidan pada ekstrak daun miana yang disimpan pada suhu sejuk mengalami peningkatan aktivitas dan setelah dua minggu penyimpanan aktivitas antioksidan mulai mengalami penurunan,hal ini tidak sejalan dengan kadar flavonoid total yang mengalami penurunan pada hari ketiga setelah
\end{abstract}


penyimpanan. Oleh karena itu diduga terdapat senyawa lain yang juga berperan memberikan aktivitas antioksidan seperti tanin yang positif terkandung dalam daun miana pada hasil pengujian metabolit sekunder dan tanin merupakan salah satu senyawa yang dapat mendukung aktivitas antioksidan dari ekstrak. Kesimpulan dari penelitian ini adalah aktivitas antioksidan daun miana mengalami peningkatan selama seminggu penyimpanan pada suhu sejuk dan mulai menurun setelah dua minggu penyimpanan.

Kata Kunci: Antioksidan; Daun Miana;IC 50.;Lama penyimpanan;Stabilitas

DOI: https://doi.org/10.25026/mpc.v8i1.295

\section{PENDAHULUAN}

Dalam kehidupan sehari-hari, manusia tidak dapat terbebas dari senyawa radikal bebas, asap rokok, makanan yang digoreng, dibakar, paparan sinar matahari yang berlebih, asap kendaraan bermotor dan obat-obat tertentu yang merupakan sumber pembentuk senyawa radikal bebas yang dapat menyebabkan terjadinya penyakit degeneratif seperti jantung koroner dan kanker $^{[1] \text {. }}$

Radikal bebas merupakan suatu molekulyang orbital terluarnya memiliki satu atau lebihelektron yang tidak berpasangan. Salah satu penyakit yaitu kanker dapat muncul karena adanya molekul tersebut, olehkarena itu organisme harus memproteksi diri dariradikal bebas. Sebagai pertahanannya organismetelah dibekali dengan antioksidan eksogen danendogen ${ }^{[2]}$.Antioksidan merupakan senyawa yang dapat menghambat reaksi oksidasi, dengan mengikat radikal bebas dan mengeliminasi senyawa radikal bebas di dalam tubuh sehingga tidak menginduksi suatu penyakit ${ }^{[3]}$.

Tumbuhan dapat berperan menghambat radikal bebas sebagai sumber antioksidan alami yang banyak terkandung dalam tumbuhan umumnya merupakan senyawafenolik atau polifenolik yang dapat berupa golongan flavonoid, salah satunya adalah Daun miana (Coleus atropurpureus L. Benth.) mengandung flavonoid yang memiliki aktivitas antioksidancukup tinggi yaitu $\mathrm{IC}_{50}$ pada ekstrak etanol daun miana 48,04 $\mathrm{ppm}^{[4]}$.Tumbuhan miana beranekaragam dari corak, bentuk, dan warna, tetapi yang memiliki khasiat sebagai obat adalah daun yang berwarna merah kecoklatan ${ }^{[5]}$.

Stabilitas aktivitas antioksidan dapat dipengaruhi oleh beberapa faktor seperti $\mathrm{pH}$, oksigen, cahaya, dan suhu. $\mathrm{pH}$ memiliki pengaruh yang sangat penting pada kestabilan antioksidan dimana penelitian sebelumnya menunjukkan stabilitas antioksidan pada tanaman miana sangat baik pada $\mathrm{pH}$ asam dan tidak stabil pada $\mathrm{pH}$ netral maupun basa $^{[6]}$. Begitu pun dengan pengaruh suhu dan lama penyimpanan ${ }^{[7]}$.

Suhu penyimpanan maupun suhu proses pengolahan dapat mempengaruhi degradasi dari senyawa yang memberikan aktivitas antioksidan ${ }^{[7]}$, salah satu contohnya yaitu pada ekstrak bunga rosella mengalami penurunan aktivitas antioksidan pada penyimpanan suhu kamar ${ }^{[8]}$ dan pada ekstrak beras ketan juga mengalami penurunan stabilitas antioksidan pada penyimpanan pada suhu kamar dengan kondisi terkena paparan sinar matahari dimana penyimpanan pada suhu dingin memberikan kestabilan yang lebih baik ${ }^{[9]}$.

Berdasarkan uraian diatas maka perlu dilakukan penelitian mengenai pengaruh lama penyimpanan terhadap 
aktivitas antioksidan ekstrak daun miana. Hal ini diupayakan agar diperoleh aktivitas antioksidan yang optimal.

\section{BAHAN DAN METODE}

\section{Bahan}

Bahan yang digunakan adalah daun miana (Coleus atropurpureus L. Benth), Etanol 96\%, Etanol p.a, DPPH, Kertas Saring , $\mathrm{AlCl}_{3}$, Natrium Asetat, Quersetin dan Aquades

\section{Pengumpulan sampel}

Sampel merupakan daun miana yang diperoleh dari Kecamatan samarinda seberang Kelurahan handil bakti

\section{Ekstraksi}

Simplisia daun miana (Coleus atropurpureus L. Benth) dimasukkan kedalam wadah toples maserasi.Kemudian dimaserasi menggunakan pelarut etanol $96 \%$ dan didiamkan selama 3 hari.Hasil ekstraksi dipekatkan menggunakan rotary evaporator hingga didapatkan ekstrak kental etanol.

\section{Rendemen Ekstrak}

Data rendemen ekstrak daun miana (Coleus atropurpureus L. Benth) pada penelitian ini diambil dari jumlah berat simplisia basah dan berat ekstrak total.

Rendemen ekstrak $=\frac{\text { bobot total } \text { ekstrak }}{\text { bobot simplisia }} \times 100 \%$

\section{Pengujian Metabolit sekunder}

Hasil ekstraksi daun miana diuji kandungan metabolit sekunder didalamnya.Setiap ekstrak daun miana diuji terhadap adanya golongan senyawa alkaloid, flavonoid, steroid, saponin, tanin dan antosianin menggunakan pereaksi yang sesuai.

\section{Stabilitas Lama Penyimpanan}

Ekstrak disimpan pada kondisi penyimpanan ekstrak suhu sejuk $8-15{ }^{\circ} \mathrm{C}$ \pm 1 bulan kemudian pengambilan sampling dilakukan pada hari ke- $0,1,3$, 7, dan 14 .

\section{Pengujian Antioksidan}

Pengujian aktivitas antioksidan menggunakan metode DPPH (1,1diphenyl-2-picrylhydrazyl) dilakukan dengan pembuatan larutan DPPH 40 ppm, penentuan panjang gelombang absorbansi maksimum, pembuatan larutan seri konsentrasi uji dari larutan stok ekstrak 500 ppm kemudian mengukur aktivitas antioksidan ekstrak daun miana dari lima seri konsentrasi yang telah dibuat yaitu $30 \mathrm{ppm}, 40 \mathrm{ppm}$, 50 ppm, 60 ppm dan 70 ppm menggunakan spektrofotometer UV-Vis, pengujian aktivitas antioksidan dilakukan pada hari ke-0, 1, 3, 7,dan 14 .

\section{Pengujian Flavonoid Total}

Penentuan kadar flavonoid total dalam ekstrak dilakukan dengan pembuatan baku quersetin dan pengukuran absorbansi ekstrak daun miana konsentrasi 500 ppm menggunakan spektrofotometer UV-Vis. Penentuan kadar flavonoid total menggunakan pereaksi $\mathrm{AlCl}_{3}$, Natrium Asetat dan Aquadest.

\section{HASIL DAN PEMBAHASAN}

Rendemen merupakan bobot total semua senyawa metabolit sekunder yang tersari dari suatu sampel atau $\operatorname{tanaman}^{[10]}$.Daun miana 200 gram diekstraksi dengan pelarut etanol 96\% menggunakan metode maserasi. Hasil rendemen ekstrak daun miana yang diperoleh yaitu sebanyak $8,5 \%$. Pelarut etanol merupakan pelarut polar golongan alkohol yang banyak digunakan dalam proses ekstraksi dan mempunyai daya ekstraksi yang baik dibandingkan pelarut lainnya ${ }^{[10]}$ serta etanol merupakan pelarut yang dapat digunakan untuk ekstraksi suatu bahan yang akan digunakan sebagai obat. 
Tabel 1. Rendemen Ekstrak

\begin{tabular}{ccc}
\hline $\begin{array}{c}\text { Bobot } \\
\text { Simplisia } \\
(\mathrm{mg})\end{array}$ & $\begin{array}{c}\text { Bobot Total } \\
\text { Ekstrak } \\
(\mathrm{mg})\end{array}$ & $\begin{array}{c}\text { Rendemen } \\
\text { Ekstrak } \\
(\%)\end{array}$ \\
\hline 200 & 17 & 8,5 \\
\hline
\end{tabular}

Pengujian metabolit sekunder dilakukan pada ekstrak daun miana hasil pengujian menunjukkan ekstrak daun miana positif mengandung flavonoid, steroid, tanin, saponin dan antosianin serta menunjukkan hasil negatif pada senyawa alkaloid berdasarkan penelitian sebelumnya pada ekstrak daun miana (Coleus blumei Benth) juga menunjukkan hasil negatif pada senyawa alkaloid ${ }^{[11]}$.

Tabel 2. Pengujian Metabolit Sekunder

\begin{tabular}{lc}
\hline Golongan Senyawa & Hasil $(+/-)$ \\
\hline Flavonoid & + \\
Alkaloid & - \\
Steroid & + \\
Tanin & + \\
Saponin & + \\
Antosianin & + \\
\hline Keterangan : & \\
$+=$ mengandung senyawa metabolit sekunder \\
$-\quad=$ tidak mengandung senyawa metabolit sekunder
\end{tabular}

Ekstrak daun miana (Coleus atropurpureus L. Benth) disimpan pada suhu sejuk yaitu sekitar $8-15^{\circ} \mathrm{C}$. Pengambilan sampling dilakukan untuk pengujian antioksidan dan flavonoid total pada hari ke-0,1,3,7 dan 14. Pemilihan penyimpanan suhu sejuk yakni dikarenakanaktivitas antioksidan pada ekstrak menunjukkan pada penyimpanan suhu rendah mampu meredam aktivitas radikal bebas yang lebih baik dibandingkan pada penyimpanan suhu tinggi ${ }^{[12]}$.

Pengujian Aktivitas Antioksidan dilakukan secara kuantitatif dengan pembuatan beberapa seri konsentrasi menggunkan metode DPPH. Metode DPPH dipilih karena merupakan metode yang sederhana, mudah, cepat dan peka serta hanya memerlukan sedikit sampel ${ }^{[13]}$ kemudian selanjutnya absorbansinya diukur menggunakan spektrofotometer UV-Vis.Ekstrak daun miana yang disimpan pada suhu sejuk (8$15^{\circ} \mathrm{C}$ ) diuji aktivitas antioksidannya pada hari ke-0,1,3,7 dan 14.

Prinsip pengukuran aktivitas antioksidan menggunakan metode DPPH ini adalah adanya perubahan intensitas warna ungu DPPH yang sebanding dengan konsetrasi larutan DPPH tersebut. Radikal bebas DPPH yang memiliki elektron tidak berpasangan akan memberikan warna ungu. Warna akan mengalami perubahan menjadi kuning saat elektronnya berpasangan ${ }^{[13]}$.

Nilai absorbansi yang diperoleh ditentukan nilai persentasi penghambatan radikal DPPH (\% inhibisi). Kemudian dari nilai \% inhibisi dapat ditentukan nilai $\mathrm{IC}_{50}$ (inhibitory concentration).Hasil $\mathrm{IC}_{50}$ yang diperoleh pada pengukuran aktivitas antioksidan yaitu pada hari ke$0,1,3,7$ dan 14 berturut-turut sebesar 70,13 ppm, 57,91 ppm, 50,91 ppm, 48,43 ppm dan 56,10 ppm, ditunjukkan pada Tabel 3. Suatu senyawa dikatakan sebagai antioksidan sangat kuat jika nilai IC $_{50}$ kurang dari $50 \mu \mathrm{g} / \mathrm{mL}$, kuat untuk IC $_{50}$ bernilai $50-100 \mu \mathrm{g} / \mathrm{mL}$, sedang jika IC $_{50}$ bernilai $100-150 \mu \mathrm{g} / \mathrm{mL}$, dan lemah jika $\mathrm{IC}_{50}$ bernilai $151-200 \mu \mathrm{g} / \mathrm{mL}$. Dari hasil tersebut menunjukkan bahwa masa penyimpanan dan pemilihan suhu penyimpanan mempengaruhi aktivitas antioksidan hal ini ditunjukkan pada penyimpanan hari ke- 0 menunjukkan nilai $\mathrm{IC}_{50}$ termasuk kategori antioksidan kuat setelah disimpan pada suhu sejuk 8$15^{\circ} \mathrm{C}$ pada hari ke-1, 3, dan 7 menunjukkan bahwa terjadi kenaikan aktivitas antioksidan yang termasuk dalam kategori antioksidan sangat kuat hal ini menunjukkan selama penyimpanan suhu sejuk tersebut aktivitas antioksidan semakin stabil dan meningkat. Kemudian mulai mengalami penurunan aktivitas antioksidan pada hari ke- 14hal ini diduga disebabkan karena 
ekstrak sudah mulai mengalami penurunan aktivitas antioksidan setelah penyimpanan selama dua minggu dimana senyawa metabolit sekunder yang aktif sebagai antioksidan mulai tidak stabil.

Aktivitas antioksidan pada ekstrak daun miana ini tidak sejalan dengan kadar flavonoid total yang mana pada penyimpanan hari ketiga telah mengalami penurunan kadar flavonoid total sedangkan aktivitas antioksidan mengalami penurunan pada hari ke-14 sehingga diduga senyawa yang berperan sebagai antioksidan tidak hanya flavonoid melainkan senyawa lainnya yaitu seperti tanin yang merupakan salah satu senyawa metabolit sekunder yang terdapat dalam daun miana dan tannin merupakan senyawa yang dapat berperan sebagai antioksidan. Hal ini dikarenakan tanin sangat erat kaitannya dengan aktivitas antioksidan dimana senyawa tanin tersusun dari senyawa polifenol yang memiliki aktivitas penangkap radikal bebas oleh karena itu dapat berperan sebagai donor atom hidrogen pada DPPH sehingga mendukung aktivitas antioksidan ekstrak ${ }^{[14]}$

Tabel 3. Pengujian Aktivitas Antioksidan

\begin{tabular}{llllll}
\hline $\begin{array}{l}\text { Hari } \\
\text { ke - }\end{array}$ & 0 & 1 & 3 & 7 & 14 \\
\hline $\begin{array}{l}\text { IC50 } \\
(\mathrm{ppm})\end{array}$ & 70,13 & 57,91 & 50,91 & 48,43 & 56,10 \\
\hline
\end{tabular}

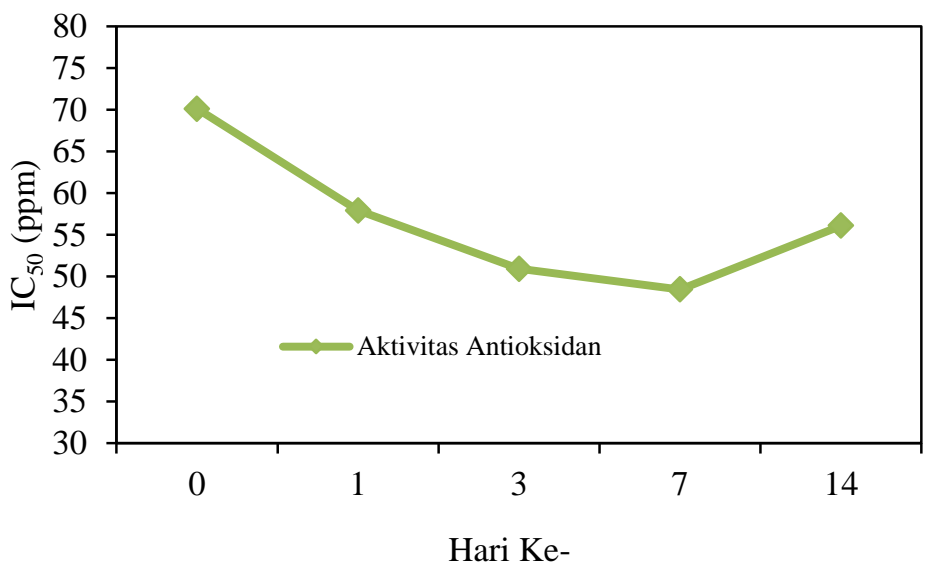

Gambar 1. Grafik nilai $\mathrm{IC}_{50}$

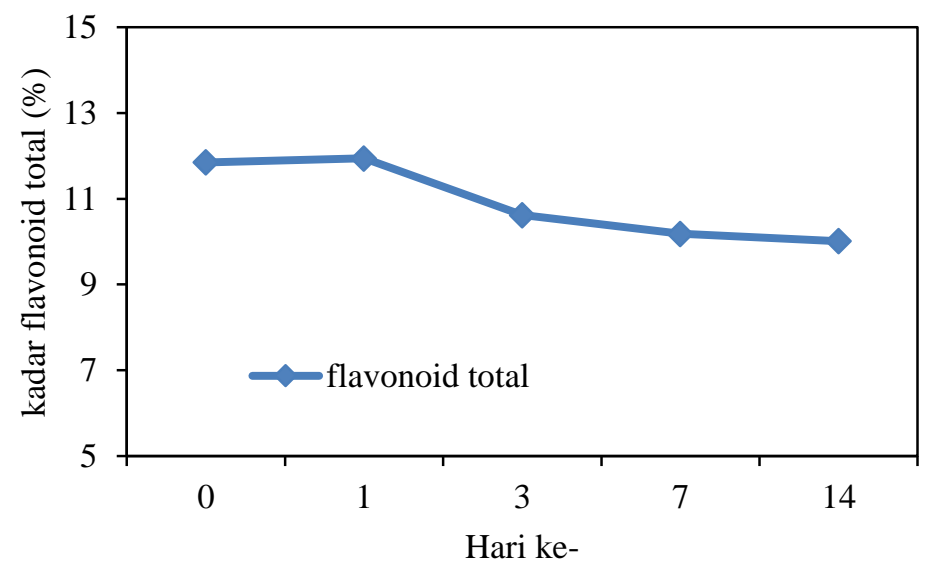

Gambar 2. Grafik Kadar Flavonoid 
Flavonoid merupakan salah satu senyawa yang terdapat dalam tanaman miana. Flavonoid dapat berperan sebagai antioksidan dengan cara mendonasikan atom hidrogennya ${ }^{[15]}$. Pengujian flavonoid total dilakukan dengan menggunakan spektrofotometer UV-Vis. Pengujian kurva baku kuersetin dilakukan untuk mendapatkan persamaan linear yang dapat digunakan untuk menghitung persen kadar, dari hasil pengujian didapatkan persamaan regresi linear $\mathrm{y}=0,0086 \mathrm{x}+(-0,0268) \quad$ dengan nilai koefisien korelasi (r) sebesar 0,998 dan nilai $r^{2}$ sebesar 0,997 serta panjang gelombang kuersetin (391 $\mathrm{nm})$. Persamaan kurva baku kuersetin dapat digunakan sebagai pembanding untuk menentukan konsentrasi senyawa flavonoid total pada ekstrak daun miana kemudian dilakukan pengujian flavonoid total pada hari ke 0, 1, 3, 7 dan 14 dari hasil pengujian pada hari ke 0 sebelum penyimpanan pada suhu sejuk $8-15^{\circ} \mathrm{C}$ yaitu flavonoid total sebesar $11,85 \%$ kemudian pada hari pertama penyimpanan pada suhu sejuk kadar flavonoid total mengalami kenaikan yaitu $11,94 \%$ hal ini menunjukkan senyawa flavonoid yang terdapat dalam ekstrak stabil, namun setelah penyimpanan hari ke-3, 7 dan 14 kadar flavonoid total mulai mengalami penurunan yaitu pada hari ke 3 sebesar $10,62 \%$, hari ke 7 sebesar $10,18 \%$ dan hari ke-14 sebesar 10,01\%, ditunjukkan pada Tabel 4. Dari hasil tersebut menunjukkan masa penyimpanan mempengaruhi kandungan flavonoid total hal ini terjadi diduga senyawa flavonoid mulai mengalami degradasi hal ini dapatdikarenakan adanya proses oksidasi flavonoid oleh oksigen yang dapat menurunkan jumlah flavonoid selama penyimpanan $^{[16]}$ dan juga senyawa antosianin yang merupakan golongan senyawa flavonoid yang terkandung pada ekstrak daun miana diduga mengalami degradasi sehingga kandungan flavonoid total mengalami penurunan hal ini dikarenakan degradasi antosianin sangat dipengaruhi oleh suhu dan lama penyimpanan ${ }^{[17]}$.

Tabel 4. Pengujian Flavonoid Total

\begin{tabular}{llllll}
\hline $\begin{array}{l}\text { Hari ke } \\
-\end{array}$ & 0 & 1 & 3 & 7 & 14 \\
\hline $\begin{array}{l}\text { Flavon } \\
\text { oid }\end{array}$ & 11, & 11, & 10, & 10, & 10, \\
total & & 94 & 62 & 18 & 01 \\
$(\%)$ & & & & & \\
\hline
\end{tabular}

\section{KESIMPULAN}

Didapatkan rendemen ekstrak etanol daun miana sebanyak 8,5\%. Positif mengandung flavonoid, tanin, saponin, steroid dan positif antosianin. Selama penyimpanan pada suhu sejuk 8$15 \%$ mempengaruhi penurunan kadar flavonoid pada hari ketiga. Dan aktivitas antioksidan mengalami penurunan setelah dua minggu penyimpanan hal ini menunjukkan bahwa flavonoid total dan aktivitas antioksidan tidak sejalan sehingga diduga terdapat senyawa selain flavonoid yang mendukung aktivitas antioksidan pada ekstrak daun miana seperti senyawa tanin yang pada pengujian metabolit sekunder positif terkandung pada ekstrak daun miana.

\section{DAFTAR PUSTAKA}

[1] Leong, P.L., and Shui. 2002. An Investigation of Antioxidant Capcity of Fruits in Singapore markerts. Food Chemistry.102 . 732-737

[2] Chludil, H.D., Corbino, G.B., and Leicarh, S.R., 2008, Soil Quality Effects on Chenopodium album Flavonoid Content and Antioxidant Potential. Journal of Agricultural and Food Chemistry.56 (13) : 50505056

[3] Kikuzaki, H., M. Hisamoto, K. Hirose, K. Akiyama, H. Taniguchi. (2002). Antioxidants Properties of Ferulic Acid and Its Related Compound. J.Agric.Food Chem. 50. 2161-2168. 
[4] Sari, Devi Dewinta. 2013. Uji Aktivitas Antioksidan Ekstrak Daun Miana (Coleus atropurpureus L. Benth) Terhadap DPPH. Skripsi Universitas

Mulawarman:

Samarinda.

[5] Dalimartha, Setiawan. 2007. Atlas Tumbuhan Obat Indonesia. Trobus Agriwidya : Bogor.

[6] Giuliana, F. E., Ardana, M., \& Rusli, R. (2015). PENGARUH $\mathrm{pH}$ TERHADAP AKTIVITAS ANTIOKSIDAN EKSTRAK DAUN MIANA (Coleus atropurpureus L. Benth). Proceeding of Mulawarman Pharmaceuticals Conferences, 1(1), 242-251.

https://doi.org/10.25026/mpc.v1i1.11 $\underline{5}$

[7] Hendry, G. A. F. and Houghton, J. D. 1996. Natural Food Colorant Second Edition.Oxford University Press: New York.

[8] Juniarka, I Gede Agus. 2011. Analisis Aktivitas Antioksidan Dan Kandungan Antosianin Total Ekstrak Dan Liposom Kelopak Bunga Rosella (Hibiscus Sabdariffa L.).Majalah Obat Tradisional.16 (3), $115-123$.

[9] Suhartatik, N. Merkuria, K. Ahmad, M. Muhammad, N.C. Sri, R. dan Endang, S. 2013. Stabilitas Ekstrak Antosianin Beras Ketan ( Oryza sativa var. glutinosa) Hitam Selama Proses Pemanasan dan Penyimpanan. Agritech.33 (4).384-389.

[10] Sari, dkk. 2017. Rendemen dan Flavonoid Total Ekstrak Etanol Kulit Batang Bangkal (Nauclea subdita) dengan Metode Maserasi
Ultrasonikasi.

Jurnal

Pharmascience. 04 ( 01) 48-53.

[11]Ridwan dkk. 2006. Kandungan Kimia Berbagai Ekstrak Daun Miana dan Efek Anthelmentiknya Terhadap Cacing Pita Pada Ayam. Institut Pertanian Bogor: Bogor.

[12] Rahmawati, Dwi P.2017. Pengaruh Waktu dan Suhu Penyimpanan Terhadap Aktivitas Antioksidan Ekstrak Daun Sembung.Skripsi UIN Syarif Hidayatullah Jakarta.

[13] Molyneux, Philip. 2004. The Use of The Stable Free Radical Diphenylpicrylhydrazyl (DPPH) for Estimating Antioxdant Activity. Songklanakarin J. Sci. Technol. 26 (2). 21-219.

[14] Malangngia, Liberty P., dkk. 2012. Penentuan Kandungan Tanin dan Uji Aktivitas Antioksidan Ekstrak Biji Buah Alpukat (Persea americana Mill.). Jurnal MIPA UNSRAT. 1 (1) 5-10.

[15] Sarker, dan Lutfin N. 2007. Kimia untuk Mahasiswa Farmasi. Pustaka Pelajar: Yogyakarta.

[16]Eveline, dkk. 2014. Studi Aktivitas Antioksidan Pada Tomat (Lycopersicon esculentum) Konvensional dan Organik Selama Penyimpanan. Jurnal Prosiding SNST.dan Antikanker. Skripsi Universitas Sumatera Utara: Sumatera Utara.

[17]Hayati, E.K., Budi, U. S., dan Hermawan, R. 2012. Konsentrasi Total Senyawa Antosianin Ekstrak Kelopak Bunga Rosella (Hibiscus sabdariffa L.): pengaruh temperature dan pH. Jurnal Kimia. 6 (2).138-147. 